VOI. XXIV

\author{
2018
}

\title{
ALGORITHM OF THE ORGANISATION OF LAND FORCES DURING TRANSPORT OF DANGEROUS GOODS
}

\author{
Ivan MINEVSKI, Yordan HRISTOV \\ "Vasil Levski" National Military University, Veliko Tarnovo Bulgaria \\ ivan_minevski@abv.bg, danchohr@abv.bg
}

\begin{abstract}
In this publication are analysed the main factors which influence the organisation and realization of transport of dangerous goods on land. An algorithm has been developed for organization of the selected type of land transport when carrying dangerous goods from manufacturer to consumer.
\end{abstract}

\section{Keywords: algorithm, dangerous goods}

\section{Introduction}

The transport sector is an extremely important component of the world economy and is often used for its development. The organization of freight transport is a difficult and complex process involving vehicle selection, optimal route preparation, handling control, documentation, fuel consumption calculation and other important procedures.

In order to meet the needs of the everevolving world economy, it is often necessary to transport dangerous goods, both at close and far distances. Dangerous goods are substances or objects the carriage of which requires the observance of precise conditions in terms of packing, loading and unloading, sorting and transport. Most often, failure to comply with these conditions may result in partial or total damage to the cargo, packaging or vehicle, as well as to severe environmental consequences.

\section{Transport of dangerous goods}

The transport of dangerous goods presents a significant risk of accidents. Therefore, the measures to ensure that this carriage is conducted under the best possible safety conditions are constantly improved. Different types of goods are transported under the conditions of dangerous goods but petroleum products, acids and fertilizers account for a major share.

The transport of dangerous goods is always associated with greater risks than ordinary ones, bearing in mind the additional hazards created by the risk factors of the cargo being transported.

When dangerous goods are transported, incidents often occur in unforeseen situations, the consequences of which may be tragic not only to people who are in the immediate vicinity of the vehicle carrying the cargo but also to the whole region.

In order to prevent and reduce the likelihood of an accident occurring in the transport of dangerous goods and, if so, in order to limit the danger and consequently the severity of the damage caused by its occurrence, a number of rules, requirements and provisions have been developed for the different modes of transport, when used for carrying dangerous goods. 
The transport of hazardous materials (hazmats) is an important problem of modern industrialized societies. For the functioning of most industrial productions are needed raw materials classified as dangerous goods. Unfortunately, most of these raw materials are not used at their point of production or extraction but transported over significant distances. When transporting raw materials classified as dangerous goods, the impact of accidental factors and events can lead to an accident, which in turn results in a spillage of the cargo being transported. Such incidents not only threaten the safety of transport, but also cause serious damage to people, infrastructure, buildings and housing, and of course not in the least for the environment. In order to prevent and reduce the likelihood of an accident occurring during transport of dangerous goods, a number of rules, requirements and provisions must be observed regarding: choices of transport; of a route; of marking; of signaling; for loading, unloading and while traveling, etc. One of the key tasks that is crucial to ensuring seamless transport is the task of risk management for the transport of dangerous goods.

\section{Land transport in carrying dangerous goods}

The main international and national documents that regulate the transport of dangerous goods by road are:

- Road transport.

ADR - European Agreement concerning the International Carriage of Dangerous Goods by Road, signed in Geneva on 30 September 1957 (Accord européen en relatif au transport international des marchandises dangereuses).

- Railway transport.

RID - Regulations on the International Carriage of Dangerous Goods by Rail (Reglement on International Transport of Ferries to Maritime Dangerous Goods). The Regulations are Annex I to the Uniform
Rules concerning International Carriage of Goods by Rail (CIM) which are in Appendix B to the Convention concerning International Carriage by Rail (COTIF) of 05.09.1980.

Rail transport is the main mode of transport in all industrialized countries in the world and plays an important role in the country's transport system. It develops in conditions of serious competition with road, air, river, sea and non-conventional modes of transport. This leads to its constant improvement through the continuous introduction of new methods of calculation and design, by introducing advanced technologies and by using modern methods of testing the railway equipment.

Typically, when using this mode of transport for freight transport, it has many advantages, the most important of which are the following:

- Facilitating long-distance travel and transport of bulky goods whose transportation is difficult or impossible with other modes of transport;

- Low transport costs resulting in reduced value of finished products;

- Ensures the rapid movement of goods from one place to another during emergencies;

- Rail transport is the safest mode of transport. Accident statistics show minimum values compared to other modes of transport;

- Railways are a strategic component of the transport infrastructure for national security;

- Rail transport provides high efficiency when transporting materials and goods over long distances;

- Rail transport is preferred for transportation of large-capacity selfpropelled equipment with high operating costs;

- When transporting different types of freight, rail transport is successfully combined with other modes of transport, i.e. rail with container, rail with road or 
even a combination of more than two types of transport.

- Disadvantages to it can be:

- The railway infrastructure requires large investments. Construction and maintenance costs are much higher than other modes of transport. In the event that traffic is not enough, investment may mean wasteful of huge resources.

- Lack of flexibility. Routes and times can not be adjusted to individual needs.

- Rail transport can not provide door-todoor services as it is linked to a particular rail network.

- Short-distance rail transport is not costeffective.

The above-mentioned qualities make rail transport particularly attractive when transporting large quantities of dangerous goods over long distances. It should be noted that it is also the main mode of transport in the organization and realization of intermodal freight transport.

In general, rail transport carries flammable liquid substances, compressed and liquefied gases, corrosives, oxidants, toxic substances, explosives, radioactive substances and other.

The impact of unforeseen factors and events can cause an accident that results in leakage of dangerous substances. Taking into account the fact that large quantities of dangerous goods are transported by rail, the incidents that could occur during the transport not only threaten the safety of the railway transport but also the life and health of the people; they could cause great material damage and are particularly harmful to the environment. It has to be said that an important condition for the safety and security of the transport of dangerous goods by rail transport is the observance of all the rules and requirements included in the normative documents regulating the performance of this type of transport. These rules must be met primarily by the consigner, the carrier and the consignee.

The development of road transport is extremely important for the functioning of the world economy and is central to the overall transport system of each country. In the last few decades of our time, road transport has emerged as the most dynamically developing transport, showing an effective interaction with scientific and technological progress. Road freight transport as part of the country's overall transport system and as a result of its rapid development is the main mode of transport in the country, serving a large share of domestic and international freight. It has gained its dynamic development due to its qualitative characteristics and has become the preferred mode of transport for many manufacturers who rely on it for the timely placement on the national and world market of the goods produced by them. The growth of the market economy and the gradual exit from the economic crisis are favorable factors for the development of road transport because of its significant comparative advantages, creating a precondition for its competitiveness to other types of transport which is demonstrated in the following:

- High maneuverability, which manifests itself in the ability to make direct shipments from vendor's store to a customer, the so-called door-to-door service. Very often, rail, air and sea transport as a rule require the use of road transport to deliver the goods to the consignee's "door";

- Fast delivery - high speeds are an advantage leading to short delivery times, especially at short and medium distances;

- Transport to small settlements and villages. Road transport is extremely useful for transporting people and goods in small towns and areas where there is no rail infrastructure or airports and ports;

- High flexibility in transport services when determining the route and timing of deliveries; 
- Quick and easy adaptation to the requirements and conditions of carriage. Depending on the route, the amount of cargo carried and the condition of the roads, the most suitable type of vehicles can be selected;

- Small capital costs. This type of transport requires considerably lower costs and investment compared to rail or air transport;

In spite of its advantages, road transport also has significant disadvantages, such as the following major ones:

- Environmental pollution due to the large amount of liquid fuels used;

- Low labor productivity due to low carrying capacity;

- High investment levels in delivery and repair costs for 1 tonne of load compared to other modes of transport;

- High probability of occurrence of traffic accident;

- Dependence on climatic and meteorological factors.

Taking into account the above mentioned advantages and disadvantages of road transport, it is reasonably considered to be the most universal mode of transport, especially for carrying dangerous goods at short distances and in urban conditions. In the course of this type of transport, incidents often occur in unforeseen situations, the consequences of which can be harmful not only for the people who are in the immediate vicinity of the freight vehicle but also for the whole region.

The dangerous goods transported pass through settlements with heavy traffic, industrial sites, residential and public buildings. Consequently, the occurrence of an accident in the transport of these dangerous goods is a prerequisite for the occurrence of significant damage and human casualties.

\section{Algorithm for the organization of the land transport of dangerous goods}

The choice of mode of transport requires an analysis of the technical and economic characteristics of the different modes of transport, with an emphasis on the following characteristics: characteristics of the means of transport, specificity of operation, economic efficiency and others. [1]

The dilemma to resolve should therefore be - whether to transport a large quantity of cargo at once using rail or carry the same quantity several times in smaller loadings by road. [2]

A major role in organizing and conducting the transport of dangerous goods at all stages (storage, handling, loading, unloading, guarding, transportation and unloading) plays the safety consultant for the transport of dangerous goods. When organizing transportation by road and multimodal transport the safety consultant needs to follow a certain algorithm in order to ensure safe transport and to avoid risks.

The algorithm (Figure 1) is compiled on the basis of the regulatory rules in the enactments and the requirements for the management of transport risks. The algorithm connections are formed by following the sequence of actions in organizing the safe transport of dangerous goods.

When carrying dangerous goods the smallest inaccuracies and mistakes in the organization can have a strong negative impact on the life and health of people, the environment, the vehicles, buildings, infrastructure, etc. In order to avoid such consequences it is necessary to observe the rules and regulations stated in the enactments. In principle, this also applies to the availability of the necessary documents and their proper completion. 


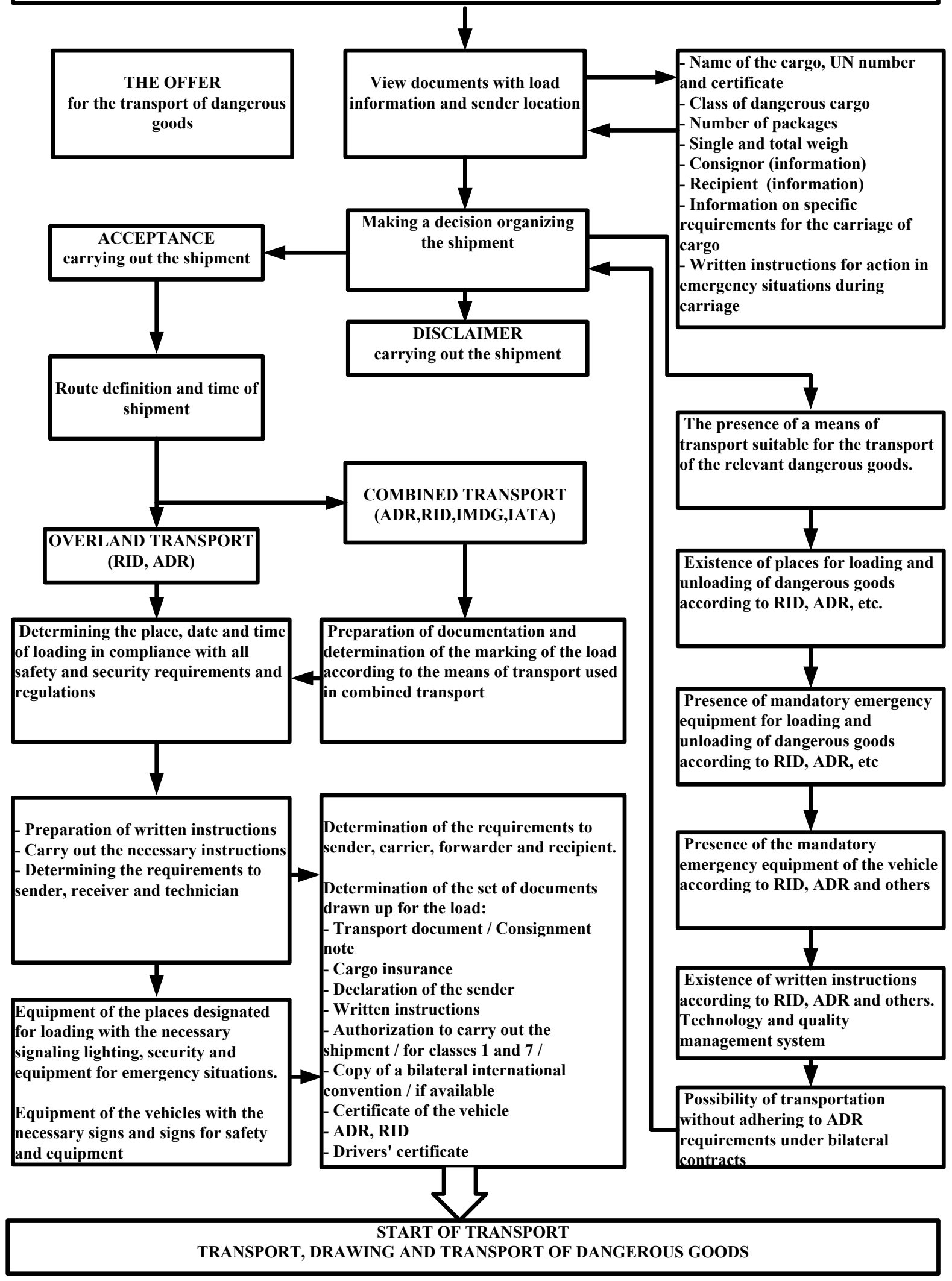

Figure 1: Algorithm for the organization of the transport of dangerous goods by road. 


\section{Conclusion}

The proposed algorithm sets the normative basis necessary for organizing and conducting the transport of dangerous goods. It allows an optimal solution to organizing the transport of dangerous goods with a selected type of road transport.

The algorithm shows in concrete terms, at each step, the defined transport organization activities. By following the steps in the algorithm, there is a minimal risk of making mistakes when deciding to conduct transport organization procedure.

Using the proposed algorithm the work of the safety consultant is greatly facilitated.

\section{References}

[1] Банабакова, В (2010) Стопанска логистика. Изд. Фабер, Велико Търново// Banabakova, V (2010) Stopanska logistika. Izd. Faber, Veliko Tarnovo.

[2] Batarliene.N., (2008) The reduction of the risk and accident probability on carriage of dangerous goods, Transport and Telecommunication, Lithuania. 